\title{
A figura do otro na educação comparada
}

\author{
Amarildo Luiz, Trevisan \\ Universidade Federal de Santa Maria - RS/Brasil \\ trevisanamarildo@gmail.com \\ Catia Piccolo Viero, Devechi \\ Universidade de Brasília - DF/Brasil \\ catiaviero@gmail.com \\ Gionara, Tauchen \\ Universidade Federal do Rio Grande - RS/Brasil \\ giotauchen@gmail.com
}

\section{Resumen}

Los estudios comparados en educación buscaron, históricamente, atender diferentes preocupaciones y abordajes teóricos pasando por la comparación de las semejanzas y diferencias entre los sistemas educativos nacionales, como estrategia para orientar las reformas educativas, hasta los estudios que buscan la producción de sentidos y de solidaridades simbólicas. Por esto, el artículo pretende destacar los rastros históricos de los estudios comparados para contextualizar la evolución de sus discusiones hasta el presente. El estudio, de naturaleza teórica, es referenciado en el abordaje hermenéutico-reconstructivo de Habermas (2003; 2004). La actualidad de la educación comparada revela que la comprensión científica ha exigido la investigación de contextos diversificados para dilucidar problemas comunes. De este modo, entendemos que al estudiar los problemas educacionales, esta puede, por medio del discurso con el otro, encontrar caminos cada vez más adecuados a nuestras experiencias junto al mundo vivido.

\section{Resumo}

Os estudos comparados em educação buscaram, historicamente, atender diferentes preocupações e abordagens teóricas passando pela comparação das semelhanças e dessemelhanças entre os sistemas educativos nacionais, como estratégia para orientar as reformas educativas, até os estudos visando à produção de sentidos e de solidariedades simbólicas. Por isso, o artigo objetiva colocar em relevo os rastros históricos dos estudos comparados para contextualizar a evolução das suas discussões até o presente. $O$ estudo, de natureza teórica, é referenciado na abordagem hemenêutico-reconstrutiva de Habermas (2003; 2004). A atualidade da educação comparada revela que a compreensão científica tem exigido a investigação de contextos diversificados de modo a elucidar problemas comuns. Desse modo, entendemos que ao se debruçar nos problemas educacionais, ela pode, por meio do discurso com o outro, encontrar caminhos cada vez mais adequados às nossas experiências junto ao mundo vivido.

Palabras clave: educación comparada; aprendizaje comunicativo; discurso, hermenéutica.

Palavras-chave: educação comparada; aprendizagem comunicativa; discurso; hermenêutica.

\section{A FIGURA DO OUTRO NA EDUCAÇÃO COMPARADA}

"A relação ao Outro continua sendo o ponto nodal, a referência da qual o comparatismo não pode abrir mão, mesmo deslocado nesses espaços ampliados, estirados, da contemporaneidade" (Malet, 2004, p. 1319).

\section{Considerações iniciais}

Os fenômenos de interdependência cultural e econômica (globalização), o enfraquecimento do Estado-Nação, a internacionalização da educação, o reconhecimento de problemas transculturais e a con- 
solidação de territórios indenitários supranacionais e infranacionais vêm potencializando a ampliação dos estudos em educaçao comparada. Historicamente, o campo esteve voltado ao atendimento de diferentes preocupações e abordagens teóricas passando pela comparação das semelhanças e dessemelhanças entre os sistemas educativos nacionais, como estratégia para orientar as reformas educativas, chegando hoje aos estudos visando à produção de sentidos e de solidariedades simbólicas.

Da mesma maneira que as Ciências Sociais e Humanas, e influenciada por essas, a Educação Comparada passou por um movimento primeiro de pertença e, depois, de oposição ao modelo positivista de ciência, expressando diferenças significativas na concepção de sujeito e objeto, natureza e cultura, particular e universal, local e global. Atualmente, embora alinhavada em diferentes enfoques epistemológicos, ideológicos e metodológicos, manifesta-se, de forma mais enfática, pelo deslocamento dos interesses de estudo dos sistemas educativos nacionais para a compreensão de processos históricos constituídos por sentidos discursivos. Pode-se dizer que a Educação Comparada passou de uma lógica de comparações e julgamentos, seguida de intervenções e direcionamentos para a compreensão dos contextos socioculturais. Segundo Malet (2004), por tempos, o discurso comparatista ignorou o outro, "[...] fazendo dele um objeto, muito mais frequentemente do que tentou compreendê-lo" (p. 1319). Segundo Hermann (2014, p. 479), essa situação se deve à herança da metafísica ocidental baseada na filosofia da identidade que criou os dualismos presente em nossa cultura, como corpo e alma, civilização e barbárie, razão e desrazão, a qual "tende a ver o outro como tudo o que se opõe às idealizações: o bárbaro, o selvagem, o infiel". Por isso, um dos desafios atuais da investigação comparada é tentar enxergar além dessa visão metafísica e perceber o outro enquanto interlocutor em pé-de-igualdade no trato com o mundo.

Mas em um cenário de globalização da economia e de internacionalização da educação, onde a transposição de modelos educacionais, de forma descontextualizada, é frequente, como fazer comparações não por meros interesses ou especulações de instituições ou países, mas pela vontade de aprender com o outro sobre educação? No contexto em que as estruturas informacionais e os indicadores de desempenho tornaram-se o princípio de inteligibilidade da coesão social, é possível a realização de trabalhos que interpelem e renovem os discursos educacionais pela possibilidade de troca discursiva entre atores educacionais em distintos espaços e contextos?

Evidenciamos, nesses questionamentos, a necessidade de dar continuidade à discussão da educação comparada enquanto campo teórico-metodológico, reintroduzindo o debate sobre a figura do outro a partir da concepção discursiva de Jurgen Habermas (2003; 2004). Referenciando-se na abordagem hemenêutico-reconstrutiva objetivamos, inicialmente, descrever suscintamente e interpretar alguns dos rastros históricos dos estudos comparados no sentido de contextualizar a evolução dos debates para, então, potencializar a discussão sobre o outro a partir das contribuições da racionalidade comunicativa proposta por esse autor. Nos propomos a realizar uma incursão filosófica voltada ao fortalecimento conceitual do campo, rosbutecendo, a partir da racionalidade comunicativa, os fundamentos que apoiam os seus objetivos. Objetivamos que no confronto entre interpretações já existentes no campo, a comparação possa ser pensada com propósito de aprendizagem mútua por meio da conversação com o outro. Ou seja, sem ficar dependente da determinação do limite dos sentidos, busca se inserir num processo de resolver problemas comunicativamente. Tal foi a guinada dada pelo autor em relação à hermenêutica filosófica, ou seja, aprender não somente com a fusão dos limites dos horizontes, mas perceber nesses horizontes potencialidade argumentativa capaz de validação de saberes.

\section{Da criação à nova organização da Educação Comparada}

Os primórdios da Educação Comparada são ligados ao período do pós-iluminismo, século XIX, marcado pelos empreendimentos de Marc-Antoine Jullien de Paris e pelos discursos dos formuladores e reformadores de políticas educacionais na Europa e nos Estados Unidos (Göergen, 1991; Carvalho, 2014). Jullien de Paris intencionava estruturar uma ciência da Educação Comparada que, fundada na fé do progresso científico e no sistema político do Estado-Nação, configuraria uma ciência quase positivista (Kazamias, 2012; Monarca, Lourenço Filho, 2004). Acreditava que a Educação Comparada deveria centrar-se em fatos e observações objetivas, com a aplicação de métodos e técnicas das ciências positivas, tendo por objetivo aprimorar a educação. Pautados por uma concepção neutral de ciência, os comparatistas buscavam definir princípios universais, os quais poderiam ser utilizados de forma generalizada em qualquer contexto (Rezende, Isobe, Moreira, 2013; Göergen, 1991; Franco, 2000; 2009). Malet (2004, p. 1303) analisa que "os dois primeiros componentes apontados no 
discurso comparatista - o determinismo e o pragmatismo - abrangem quatro tipos de abordagens: positivista e "naciocentrista", por um lado, e evolucionista e intervencionista, por outro", constituindo o programa científico e societal da modernidade. A comparação, erigida como princípio metodológico para a abordagem naturalista dos fatos, tomava como objeto de estudo os sistemas educativos nacionais como unidades de análise estável e independente, caracterizando uma "concepção descritiva e estática do conhecimento" (Malet, 2004, p. 1304).

$\mathrm{Na}$ intenção de explicar os sistemas educativos nacionais, os comparatistas passam a interessar-se por desvendar os princípios de sua organização. Menos preocupada em fornecer um método para o campo, mas ainda influenciada pelo positivismo, a abordagem "naciocentrista" intencionava caracterizar e conhecer os sistemas educativos estrangeiros como um meio para melhor organizar e prosperar o seu próprio sistema educativo (Carvalho, 2014). Contudo, no início do século XX, são tecidas advertências sobre a importação ou transposição de modelos educativos, em contextos culturais diferenciados. É por isso que Monarcha e Lourenço Filho (2004, p. 25) vão denotar que "até a guerra de 1914-1918, os estudos comparativos de educação ofereceram feição eminentemente descritiva".

No entanto, os primeiros movimentos da Educação Comparada, marcados por intenções progressistas e modernizadoras, serão transformados pelas necessidades de reconstrução e de reforma da educação no pós-segunda guerra mundial. Malet (2004, p. 1307) destaca que as nações "[...] investiram a Educação Comparada como um ideal de intercompreensão e de pacificação das relações internacionais, o qual favoreceu a criação dos principais organismos internacionais". As preocupações de solidariedade das nações situam o componente pragmático do projeto moderno de unificação nacional. Com essa tendência de convivência pacífica, a Educação Comparada é utilizada como ferramenta para a tomada de decisões e instrumento para as políticas reformadoras. Cabe-nos salientar que essa tendência reveste-se, ainda, de maior significado se considerarmos que "o Estado continua a ser o principal agente de seleção e tradução dos imperativos globais [...]. Assim, a seleção e a tradução de imperativos educacionais globais são, principalmente, processos locais que estão sujeitos às restrições de atores e de condições locais" (Law, 2012, p.315).

Distanciando-se da ambição de generalização e o consensualismo, mas ainda buscando a cientificidade do projeto original, a Educação Comparada, na abordagem do evolucionismo social, investe suas forças na fé do desenvolvimento social e na resolução dos problemas dos contextos. Do mesmo modo, amplia-se o interesse pela assistência econômica e tecnológica aos países em desenvolvimento. Essas perspectivas, fortemente vinculadas e financiadas pelos organismos internacionais, caracterizam-se pelo uso de pesquisas quantitativas sistemáticas como ferramenta para o planejamento educacional (Matheou, 2012).

Malet (2004, p. 1309) considera que essa tendência dos organismos internacionais "é de certa forma menos pragmática, pois mais descritiva", preocupando-se em avaliar e acompanhar as reformas educacionais e melhorar os sistemas de informação, revelando-se mais intervencionista. Neste movimento de avaliação da eficiência dos sistemas educativos verifica-se a imposição de um espaço ampliado (mundial) para a compreensão dos fenômenos educativos, simplificando as especificidades das culturas e histórias nacionais, os quais favoreceram os paternalismos e assistencialismos econômicos e políticos, bem como a vigência de modelos de sujeição.

Dificilmente conciliáveis, os interesses e as práticas discursivas dos diferentes atores sociais, os quais se vinculam em maior ou menor incidência às abordagens até aqui contempladas, constituíram um fator de fragilização do campo e um terreno fértil para o comparatismo crítico. Nesse sentido, estrutura-se a concepção crítica, fundamentada no marxismo como uma reação contra as concepções consensualistas que incorporam formas contemporâneas de colonialismo. Neste enfoque, os processos de mudança social são o principal tema em estudo. Os comparatistas, vinculados a esta abordagem, são contra as ações realizadas pelas organizações internacionais e pelas políticas conduzidas para os países do terceiro mundo, pois estas, ligadas ao funcionalismo estrutural, "seriam responsáveis pela legitimação de uma ordem social injusta que internamente se manifestava na manutenção das desigualdades e externamente na criação de situações de dependência" (Ferreira, 2009, p. 156). No plano metodológico, os estudos expressam o deslocamento da concepção exógena da comparação para o esclarecimento dos fenômenos educativos locais vistos a partir da totalidade social.

Apostando numa perspectiva sócio-histórica de Educação Comparada, e influenciado pelas diferentes perspectivas de autores como Ricoeur, Foucault e Habermas, surge no campo a abordagem histórico-hermenêutica propondo a análise não dos fatos em si, mas dos seus sentidos históricos, se debruçando sobre as comunidades discursivas entendidas como saberes particulares historicamente 
formados. Desconfiando das ideologias progressistas e exógenas que, por muito tempo, trabalharam o campo, essa tendência contemporânea substitui progressivamente um modelo contextual e pragmático por um modelo textual que traduz a centralidade do discurso na construção dos fenômenos educativos. A ideia é compreender a natureza subjetiva e os sentidos que lhes são atribuídos pelos diferentes atores (individuais e coletivos) nos seus imaginários sociais e também compreender 0 universal e o particular, não como dois processos distintos, mas derivados de um mesmo processo histórico (Carvalho, 2014).

Podemos dizer desse modo que o campo da Educação Comparada expandiu sua perspectiva de análise, estando não mais restrito aos meios geográficos e políticos, mas imerso na multiplicidade de práticas discursivas que oferecem sentidos às comunidades humanas. Não objetiva identificar pontos comuns e incomuns, mas significados culturais que se convergem nos e entre os espaços. Sendo assim, o movimento crítico das concepções objetivas e fechadas, somado à inclusão do outro enquanto inteligibilidade, sentido e identidade, influenciaram, de forma decisiva, as suas discussões e os encaminhamentos (Carvalho, 2014, Franco, 2000). O entendimento é de que não existe uma objetividade que garanta a ação correta dos sujeitos, mas sim campos de significados construídos em situações e realidades específicas por meio de práticas discursivas.

Neste sentido, Cowen (2012) considera que um dos esforços da Educação Comparada tem sido redefinir conceitos interpretativos para a compreensão das novas relações entre o nacional, o internacional e o global. Explica que na Educação Comparada, "ler o global" "[...] significa a seleção de uma agenda de trabalho acadêmico, a identificação de ansiedades e perplexidades inseridas em uma interpretação das partes estrangeiras do mundo que são vistas - no sentido de que tais localidades tornam-se deliberadamente visíveis" (Cowen, 2012, p. 391). Afirma que "o problema clássico da educação comparada é constituído de três momentos: (i) transferência; (ii) tradução - o problema duplamente osmótico da inclusão de ideias, princípios, políticas e práticas educacionais em um lugar e de inseri-los em outro contexto social" e "[...] (iii) a transformação do fenômeno educacional, à medida que cresce socialmente, osmoticamente nesse novo contexto social" (Cowen, 2012, p.409-410).

Podemos dizer que as transformações da Educação Comparada foram desencadeadas por um conjunto de críticas à racionalidade moderna, sendo marcadas, principalmente nos últimos tempos, pelo reconhecimento do outro ou do estranho enquanto texto a ser compreendido. Na sequência de denúncias e propostas, autores de diferentes linhas teóricas perceberam a heterogenia e a diversidade da cultura mundial, passando a reclamar ressignificação da vida a partir das múltiplas formas discursivas. Trata-se de uma mudança que envolve uma série de contraposições carregadas de implicações práticas e teóricas e que representa o foco das discussões atuais apresentadas pelas diferentes abordagens teóricas que dão base aos estudos comparativos. Segundo Malet (2004, p.1318), "[...] está claro que um componente fundador do projeto e do discurso comparatistas está em vias de ser (re) pensado de acordo com as mudanças civilizacionais contemporâneas [...], a educação comparada não pode abrir mão, é a figura do Outro".

Nesse cenário, os desafios atuais da Educação Comparada se colocam, principalmente, no campo da percepção do outro e de suas diferenças culturais e imaginárias como um outro e não idêntico a si mesmo. Não é mais pretensão da maioria dos estudos copiar modelos estrangeiros, como buscou Isaasc Kandel (1933), por meio da perspectiva histórica, nem oferecer um tratamento estatístico dos dados, como buscaram Noah e Eckstein (1969), mas construir outros significados e histórias a partir da multiplicidade dos campos discursivos. Não se intenciona produzir saberes generalizáveis e inabaláveis, mas interpretações comprometidas com a pluralidade de sentidos e seus respectivos contextos. Tal virada trouxe para a Educação Comparada a liberdade de criação e a tolerância com os diferentes estilos de vida, embora esses se encontrem deslocados em espaços cada vez mais alargados.

No entanto, apesar de reconhecer a importância da inserção dessa tradição metafísica no campo da Educação Comparada, entendemos que diante do retraimento das identidades culturais, resultante do processo de globalização e do enfraquecimento do Estado-Nação, os desafios não se esgotaram, tendo em vista a necessidade de dar conta de uma realidade intramundana. Nesse sentido, como aduz Hermann (2014, p. 480): "Os esforços educacionais de ir ao encontro da singularidade do outro exigem ultrapassar uma visão metafísico apropriadora e compreender os limites da consciência intencional". Apesar dos esforços de reconhecimento das singularidades, essas ainda aparecem comprimidas por uma cultura globalizada, sem que possam participar das decisões em torno das preocupações comuns. "Trata-se de compreender o outro a partir dele próprio e, por exclusão, reconhecer-se na diferença" (FRANCO, 2000, p. 200). Por isso, Rezende, Isobe e Moreira (2013, p. 236), 
alinhadas a esta preocupação com o outro, sugerem que a "diferenciação, a diversidade e a alteridade" sejam incorporadas como categorias analíticas dos processos comparativos.

É nesse sentido que propomos discutir a possibilidade de renovar a compreensão da figura do outro ou do estrangeiro (muitas vezes concebido como objeto/texto a ser compreendido), situando-o como segunda pessoa participante do discurso e tendo, como fundamento de análise, a teoria discursiva de Jurgen Habermas. Tratamos de debater o poder da participação argumentativa do outro para uma aprendizagem intranacional/intracontextual no que se refere aos problemas que se colocam para além dos textos e contextos particularistas.

\section{Educação Comparada: da compreensão dos sentidos à aprendizagem comunicativa}

Está claro que a ideia predominante no campo é de que não é mais possível pensar em estudos comparativos sem considerar a história, os campos discursivos, a preocupação com as diferenças e com o outro ou estranho. O outro passa a ser visto em sua tradição culturalmente específica, tendo em vista que mesmo uma nação/região é composta por diferentes formas de vida. Mais importante que responder aos fatos educativos, é preciso compreender como se desenvolvem discursivamente as identidades e os sentidos das comunidades humanas. É necessário compreender os significados plurais determinados pelos horizontes discursivos do qual fazem parte, oriundos da sensibilização diante das diferenças socioculturais.

No entanto, considerando o fato de não termos mais acesso aos dados dos sentidos não interpretados, tendo em vista que a realidade só pode ser acessada por meio da linguagem, perguntamos se a compreensão dos sentidos discursivos seria suficiente para a aprendizagem no campo educacional por meio dos estudos comparados, já que o outro estaria subjugado pela interpretação do sujeito discursivo? Questionamos se a Educação Comparada não poderia caminhar para além da compreensão dos textos/contextos específicos, contribuindo para uma abordagem participativa do outro no sentido de aprimorar a compreensão sobre as novas formas de lidar com o mundo? Embora concordando com os encaminhamento do campo, buscamos discutir a possibilidade/necessidade de renovar a figura do outro, no sentido de oferecer a esse a possibilidade de contribuir mais efetivamente no tratamento dos problemas vivenciados. Ou seja, oferecer aos estudos comparados a oportunidade de crítica e de respostas práticas às ações perturbadoras do mundo.

Tal é o que propomos discurtir por meio teoria discursiva de Habermas (2003, p. 39), especialmente quando explica que as expressões de sentido podem ser identificadas "numa perspectiva bifocal, tanto como uma ocorrência observável, quanto como a objetivação inteligível de um significado", sendo essa última dependente da participação na ação comunicativa. A interlocução exige condições de comunicação, permitindo a compreensão do que é dito sobre o caso por meio da participação no agir comunicativo. Ou seja, a expressão de sentido deve ser inteligível para falantes e ouvintes e demais membros da comunidade linguística que está sendo interpretada, e isso só é possível pela conversação para além dos limites do estritamente objetivado.

Podemos dizer que, na Teoria da Ação Comunicativa (2012), a hermenêutica assume uma postura reconstrutiva, pois passa a se ocupar não apenas da compreensão da linguagem enquanto reprodução cultural, mas como integração social de diferentes atores em interação diante da necessidade do mundo vivido. Nesse sentido, a compreensão passa a ser possível pela participação em processos discursivos, exigindo do intérprete a apresentação das razões do argumento apresentado. Ou seja, as razões enunciadas pelo ator precisam ser julgadas por uma posição negativa ou positiva frente ao outro. É nesse ponto que o outro sai do confinamento da sua tradição e aparece como figura participante na enunciação (racional) dos proferimentos. É o outro enquanto figura participante da avaliação das pretensões de validade que introduz a possibilidade de crítica frente às interpretações desviantes. O significado dos enunciados passa ser determinado "pelas condições de validade e não pelas condições de verdade, como definido na semântica formal". (Habermas, 2004, p. 71).

O outro como participante do discurso comparece, portanto, como elemento central na teoria comunicativa de Habermas (2012) e isso é fundamental para dar conta da sua posição diante dos desafios atuais dos estudos comparados, não mais como participante dialógico exclusivamente, mas ativo também no trato discursivo sobre algo no mundo. Foi nesse sentido que a ação comunicativa deu o "verdadeiro relevo ao papel crítico que desempenham as segundas pessoas aos tomar posição ante pretensões de validades reciprocamente levantadas". (Habermas, 2004, p. 14). 
Na obra Verdade e Justificação, Habermas realiza uma reviravolta na sua teoria comunicativa, defendendo um sentido mais pragmático para o discurso na tentativa de explicar a possível interação entre abertura para o mundo e os processos intramundanos de aprendizagem. Nesse sentido, permite o tratamento discursivo a partir de uma suposta base objetiva comum. Segundo ele, aprendemos não apenas no discurso com o outro, mas também na prática junto ao mundo real colocado como resistências às nossas interpretações. Aprendizagem esta não apenas histórica, mas também evolucionária, não natural no seu sentido estrito (de Darwin), mas um natural fraco dependente da experiência com o mundo e da interação discursiva. Segundo o autor "a faticidade das limitações em que nos esfregamos no trato cotidiano como experimental manifesta a resistência dos objetos a que nos referimos quando afirmamos fatos sobre eles. Por isso, supomos o mundo objetivo como sistema para referências possíveis - como conjunto de objetos, não de fatos" (Habermas, 2004, p. 35)

A experiência da ação diante da suposição de um mundo idêntico para todos coloca em dúvida as nossas interpretações e a experiência discursiva com o outro. Desse modo, o conhecimento é visto como um processo de aprendizagem teórico e prático, em que "a interação da revelação do mundo e dos processos intramundanos de aprendizagem deveria funcionar de modo simétrico" (Habermas, 2004, p. 83). Ainda segundo o autor,

a experiência que se apresenta em enunciados empíricos não é mais derivada introspectivamente da faculdade subjetiva da "sensibilidade", por meio da auto-observação do sujeito cognoscente. Ela é agora analisada da perspectiva de um ator envolvido, no contexto que põe à prova as ações guiadas pela experiência. (Habermas, 2004, p.19).

A experiência deixa de ser um campo empírico fundamentado em sentidos simplesmente, para se tornar um espaço de referência para as compreensões discursivas. Nesse sentido, a Educação Comparada produziria não apenas interpretações subjetivas dos sentidos oriundos dos textos, mas teria no outro a possibilidade de troca ou acerto argumentativo sobre algo. "O controle da ação pelo sucesso não substitui a autoridade dos sentidos em sua função de garantir a verdade. Mas dúvidas empíricas suscitadas pela perturbação de uma ação podem ativar discursos que levem a interpretações corretas" (Habermas, 2004, p. 20). Teria como prioridade epistemológica não apenas a teoria, mas a experiência prática, portanto. Como tudo é interpretação e, portanto, não há mais nada a ser alcançado fora da linguagem, a experiência focada somente na produção de sentidos perderia exclusividade na compreensão.

Habermas apresenta a teoria discursiva no intuito de permitir a legitimação para além das compreensões dos contextos lidos somente enquanto textos, pois entende o discurso como possibilidade de uma aprendizagem sempre melhorada pelo embate crítico entre as múltiplas interpretações, fruto das diferentes experiências com o mundo. Segundo o autor, "do ponto de vista pragmático, os conhecimentos resultam do processamento inteligente de decepções performativamente vivenciadas" (Habermas, 2004, p. 20). Tal é o que pensamos agregar às discussões das perspectivas comparativas: apresentar o outro na posição de segunda pessoa do discurso e retomar a prática enquanto referência e prova das decisões intersubjetivas.

O outro não mais como objeto de investigação a ser compreendido e a prática não mais como preocupação secundária ou desnecessária dos estudos. Isso não significa retomar o pragmatismo utilitário já superado pela área, mas um pragmatismo colocado como referência e espaço de teste dos acertos racionais alcançados. Habermas (2004, p. 43) justifica essa posição alertando que "é apenas com a transição da ação para o discurso que os participantes adotam uma atitude reflexiva e, à luz de razões pró e contra apresentadas, disputam pela verdade tematizada de enunciados controversos".

Para o autor, a experiência cotidiana não dá conta de tratar os problemas, mas comunica a falha das nossas formas de lidar com o mundo. No entanto, é apenas no discurso que encontramos a possibilidade de resolver as nossas interpretações equivocadas. O conhecimento é visto como aprendizagem que acontece de maneira cíclica entre a experiência com o mundo e a experiência discursiva com o outro. Como afirma Habermas (2004, p. 24), "a ascensão da ação ao discurso significa que os recursos do mundo da vida podem ser mobilizados em toda a sua amplitude para o processamento cognitivo dos problemas que se põem no trato prático com o mundo". 


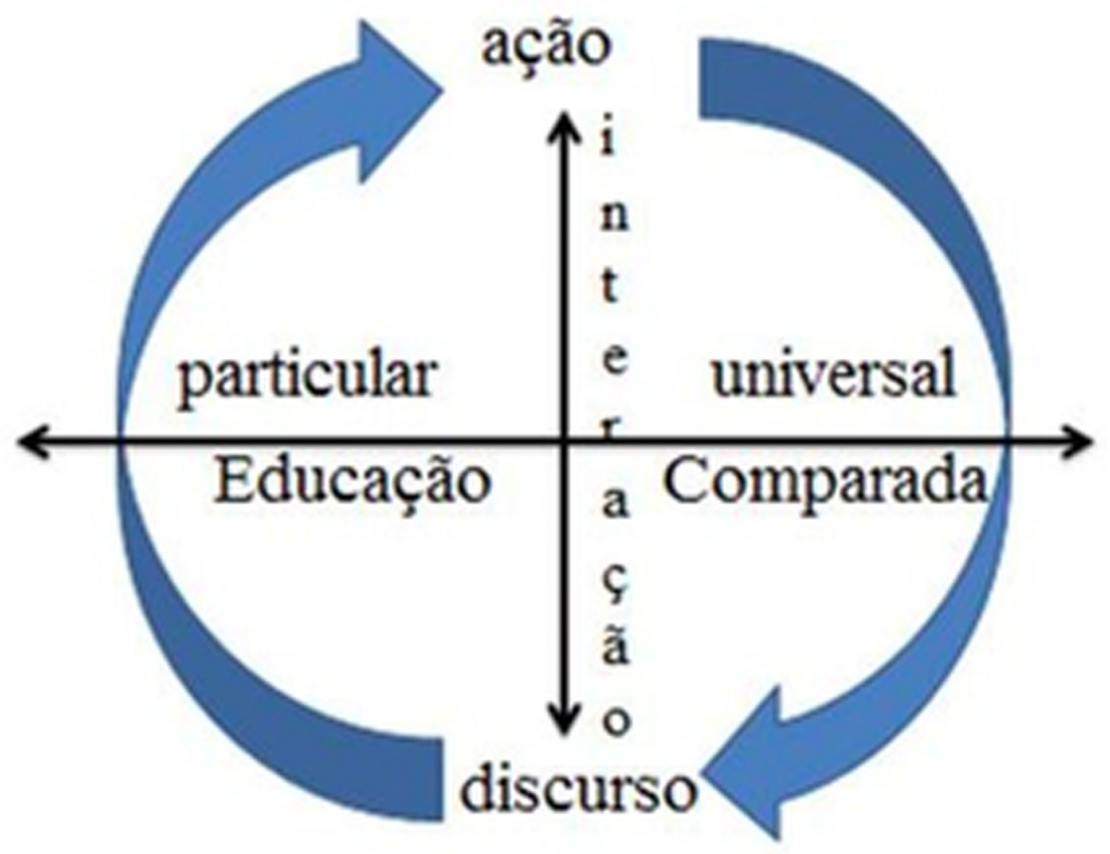

Fonte: Elaborado pelos autores.

Da mesma forma que os comparatistas hermenêuticos, a verdade, para Habermas não pode mais ser entendida como correspondência de algo no mundo. No entanto, não concorda que a verdade possa ser reduzida à compreensão dos contextos discursivos. O propósito do autor é permitir, por meio da suposição objetiva de mundo comum, o tratamento dos problemas ordinários numa conversação para além dos universos próprios de cada cultura. Para o autor,

a realidade não é algo a ser retratado; ela não se faz notar senão performativamente, pelas limitações a que estão submetidas nossas soluções de problemas e nossos processos de aprendizado - ou seja, como totalidade das resistências processadas e das previstas" (Habermas, 2004, p. 35).

São os sujeitos capazes de respostas e contradições os responsáveis pelos saberes no mundo. A aposta é de que ampliando as compreensões sobre o mundo, os preconceitos em relação a grupos poderiam ser minimizados, reduzindo a distância entre os indivíduos, sem retrair as diferenças. Ainda segundo o autor, as correções culturais dependem da força das experiências vividas que transcende os contextos particulares. Trata-se de uma orientação universalizada que descentra os saberes culturais, em favor da construção de uma cultura comum de aprendizagem mútua. Desse modo, para ele

a expressão "intersubjetivo" não se refere mais ao resultado de uma convergência observada de pensamentos ou representações de diferentes pessoas, mas à comunhão prévia - pressuposta da perspectiva dos próprios participantes - de uma pré-compreensão linguística ou de um horizonte do mundo da vida no interior do qual os membros de uma comunidade linguística se encontram antes mesmo de se entender sobre algo no mundo (Habermas, 2004, p. 240).

A compreensão é de que existe na linguagem um núcleo universal, no qual os participantes da interação discursiva conseguem chegar a um entendimento mútuo. Segundo autor, "na medida em que os falantes se orientam por pretensões de validade incondicional e supõem uns dos outros plena responsabilidade, seu alvo está além de todos os contextos contingentes e meramente locais" (Habermas, 2004, p. 25). A fundamentação das opiniões empíricas com o auxílio de outras opiniões é o que permite sistemas de aprendizagem, cada vez mais, bem-sucedidos. 


\section{Considerações finais}

A atualidade dos estudos comparados revela que a compreensão científica tem exigido a investigação de contextos diversificados de modo a elucidar problemas comuns. Desse modo, ao se debruçar nos problemas educacionais, ela pode, por meio do discurso com o outro, encontrar caminhos cada vez mais adequados às nossas experiências mundanas. Isso porque, não podendo mais compreender os processos educacionais por fatos objetivos, mas especialmente por meio da linguagem, tendo-se no discurso a oportunidade de renovar os saberes da área pelas objeções dos outros interlocutores. Para Habermas (2004, p. 259), trata-se de "traduzir as abaladas certezas da ação em enunciados problematizados (...) e retraduzir asserções discursivamente justificadas em certezas da ação restabelecida".

Desse modo, a tarefa do comparatista seria a de se inserir a aprendizagem comunicativa em busca do tratamento dos problemas decorrentes do mundo. Ou seja, permitir uma conversa de sentido com o outro, tendo em vista a mesma referência supostamente objetiva. Trata-se de uma possibilidade de ampliar os saberes discursivos realizada na abertura para o mundo, enraizada na pré-interpretação acordada. Seria caminhar para além da compreensão do sentido ou interpretação do outro, dirigindo-se a um processo de aprendizagem discursivo, porém pragmático, visando sempre melhores argumentos no tratamento cooperativo dos problemas no mesmo mundo. Além disso, por meio da abertura teórica e metodológica também poderia ser potencializada a (re)interação de saberes provenientes das diversas áreas científicas.

Pela conversação entre as diferentes interpretações, à luz do mesmo objeto, é possível aprender com o outro, ampliando as oportunidades de melhorar as compreensões fazendo justiça às necessidades do mundo vivido. Nesse aspecto há um acréscimo em relação a visão do outro pretendida pela hermenêutica tradicional. Ou seja, não há uma permanência da discussão no sentido textual dos proferimentos, mas há uma tentativa de fazer avançar a consideração para entender o outro como segunda pessoa participante do discurso. Ou seja, a referência ao outro não fica a meio do caminho, já que vincular às impressões de sentido aos textos impede a possibilidade de aprendizagem interativa. E, menos ainda, preso à metafísica da identidade, responsável historicamente pelas diferentes formas de exclusão do outro. Trata-se, assim, de desenvolver saberes mais confiáveis na educação, permitindo, por meio das diferentes experiências interpretativas com o mundo, uma aprendizagem comunicativa sempre melhorada e aberta às necessidades culturais e históricas. Ou seja, perceber nos estudos comparados uma possibilidade de desenvolver caminhos mais críticos e reflexivos, percebendo o outro/estrangeiro como um interlocutor contribuinte na revisão das decepções vivenciadas. Habermas (2004, p. 38) está certo de que a

nossa capacidade de conhecer não pode mais, como supunha o mentalismo, ser analisada independentemente da capacidade de falar e agir, pois nós, também enquanto sujeitos cognoscentes, sempre já nos encontramos no horizonte de nossas práticas do mundo da vida.

Nesse sentido, a tarefa dos estudos comparados seria realocar o outro enquanto participante do discurso universal e, ao mesmo tempo, conciliar as experiências do discurso com as práticas cotidianas. Trata-se de uma possibilidade de renovar os saberes mundanos que não mais atendem às necessidades das novas formas de lidar com a realidade. A proposta é elucidar as novas exigências colocadas aos estudos comparados por meio da articulação entre o discurso e a ação, o particular e o universal, enquanto movimento cíclico de aprendizagem comunicativa que passa pela recepção do outro, situado como segunda pessoa do discurso.

Gagnebin (2000, p. 101) percebe essa questão ao exemplicar que, mesmo no terreno das catástrofes humanas, como a Shoah, o genocídio armênio, ou pelo estudo de outros genocídios menos conhecidos, "o alvo das comparações não consiste em estabelecer vagas semelhanças, mas sim em mapear as diferenças e as especificidades". E que a finalidade desse método comparatista é a comparação entre a história do presente e do passado, o que engloba, segundo ela, "a história da recepção do saber" (Gagnebin, 2000, p. 102). Nesse sentido, a autora questiona como um livro, como o de Primo Lévi É isso um homem, publicado em 1947, tenha caído no esquecimento para ser redescoberto somente na segunda edição nos anos sessenta.

Portanto, mesmo sendo praticamente um consenso na área de educação comparada que o objetivo não deve ser mapear as diferenças, mas sim compreendê-las, é importante perceber que tal posição pode levar esses a diferenciar análises guiadas apenas pelas estatísticas objetivantes, ou somente 
pelas interpretações que podem conferir relatividade às diferentes posições discursivas. De outra maneira, eles podem questionar também, como no caso acima citado, se o outro está se pronunciando ou não a esse respeito no devido momento histórico, tendo capacidade de auxiliar na compreensão e/ou explicitação, ou ainda na negação dos significados atribuídos. Isso significaria retomar o espaço da esfera pública transnacional para que as decisões não se concentrem ou se tornem reféns de interesses particularistas, mas façam parte de uma aprendizagem interativa entre interesses contextualistas e universais que encontrem no mundo da vida a sustentação para o entendimento.

\section{Referencias bibliográficas}

CARVALHO, E. J. G. Estudos comparados em educação: novos enfoques teóricometodológicos. Acta Scientiarum Education, v. 36, n. 1, p. 129-141, Jan.-June, 2014.

COWEN, Robert; KAZAMIAS, Andreas M.; ULTERHALTER, Elaine. (Orgs.) Educação comparada: panorama internacional e perspectivas. v.1. Brasília: Capes/ UNESCO. 2012.

(Orgs.) Educação comparada: panorama internacional e perspectivas. v.2. Brasília: Capes/ UNESCO. 2012.

FERREIRA, Antônio Gomes. O sentido da educação comparada: uma compreensão sobre a construção de uma identidade. MARTINEZ, Silvia Alicia; SOUZA, Donaldo B. (Org). Educação Comparada: rotas de além-mar. São Paulo: Xamã, 2009.

FRANCO, M. C. Quando nós somos o outro: questões teórico-metodológicas sobre os estudos comparados. Educação \& Sociedade. Ano XXI, no 72, p. 197-230, agosto/2000.

Estudos comparados: sua epistemologia e sua historicidade. Revista Trabalho Educação e Saúde, Rio de Janeiro, v.7, suplemento, p.129-151, 2009.

GAGNEBIN, Jeanne Marie. Palavras para Hurbinek. In.: NESTROVSKI, Arthur; SELIGMANN-SILVA, Márcio. Catástrofe e representação. São Paulo: Escuta, 2000.

GÖERGEN, Pedro L. Educação Comparada: uma disciplina atual ou obsoleta? Campinas, Revista Pro-Posições, Revista da Faculdade de Educação, vol. 2, N. ${ }^{\circ} 3$, dez, 1991, p. 6-19.

HABERMAS, Jürgen. Consciência moral e agir comunicativo. Rio de janeiro: Tempo Brasileiro, 2003. Verdade e justificação: ensaios filosóficos. São Paulo: Loyola, 2004. Teoria da ação comunicativa, 1: racionalidade da ação e racionalização social. São Paulo: Ed. WMF Martins Fontes, 2012. Teoria da ação comunicativa, 2: sobre a crítica da razão funcionalista. São Paulo: Ed. WMF Martins Fontes, 2012.

HERMANN, Nadja. A questão do outro e o diálogo. Revista Brasileira de Educação (Impresso), v. 19, p. 477-493, 2014. Breve investigação genealógica sobre o outro. Educação \& Sociedade (Impresso), v. 32, p. 137-149, 2011.

KANDEL, Isaac.Comparative education.Boston: Houghton Miffin, 1933.

KAZAMIAS, Andreas. Educação comparada: uma reflexão histórica. In: COWEN, Robert; KAZAMIAS, Andreas M.; ULTERHALTER, Elaine. (Orgs.) Educação comparada: panorama internacional e perspectivas. v.1. Brasília: Capes/ Unesco. 2012.

MALET, Régis. Do estado-nação ao espaço-mundo: as condições históricas da renovação da educação comparada.Educação e. Sociedade. 2004, v.25, n.89, p. 1301-1332.

MATTHEOU, Dimitri. O paradigma científico na Educação comparada. In: COWEN, Robert; KAZAMIAS, Andreas M.; ULTERHALTER, Elaine. (Orgs.) Educação comparada: panorama internacional e perspectivas. v.1. Brasília: Capes/ Unesco. 2012.

LAW, W. O estado desenvolvimentista, mudança social e educação. In: COWEN, R. Introdução: o nacional, o internacional e o global. In: COWEN, Robert; KAZAMIAS, Andreas M.; ULTERHALTER, Elaine. (Orgs.) Educação comparada: panorama internacional e perspectivas. v.1. Brasília: Capes/ Unesco. 2012. 
MONARCHA, Carlos; LOURENÇO FILHO, Ruy. Educação comparada. Brasília: MEC/Inep, 2004.

NOAH, Harold; ECKESTEIN, Max. Toward a science of comparative education. Londres: Macmillan, 1969.

REZENDE, V.M.; ISOBE, R.M.R.; MOREIRA, F.A. Investigação comparada em educação: aspectos teóricos e metodológicos. Revista Educação e Políticas em Debate - v. 2, n. 1 - jan./jul. 2013.

SCHRIEWER, J. Sisterna Mundial e Inter-Relacionamento de Redes: a Internacionalização da Educação e o Papel da Pesquisa Comparativa. Revista Brasileira de Estudos Pedagógicos. Brasília, v. 76, n.182/183, p. 241-304, jan./ago. 1995. 